\title{
Use of an accelerated protocol for rapid analysis of iron overload in the heart and liver: the All Iron Detected (AID) Multicenter Study
}

\author{
Juliano L Fernandes ${ }^{1,2^{*}}$, Maria Helena A Siqueira ${ }^{9}$, Karina T Nobrega de Oliveira ${ }^{3}$, Luiz Francisco Avila ${ }^{4}$, \\ Ilan Gottlieb ${ }^{5}$, Marly U Lopes ${ }^{6}$, Andre M Fernandes ${ }^{7}$, Ralph Strecker ${ }^{8}$, Andreas Greiser ${ }^{10}$
}

From 18th Annual SCMR Scientific Sessions

Nice, France. 4-7 February 2015

\section{Background}

Magnetic resonance imaging has become an essential tool in the management of patients with iron overload. Most of these patients are located in under-developed regions of the world where access to scanners is limited. Effective use of resources is therefore mandatory especially in very densely populated areas. We sought to assess if an accelerated protocol under ten minutes for iron overload assessment in the heart and liver using automated sequences and analysis would be feasible and accurate in a multicenter study.

\section{Methods}

Seven centers participated in the study enrolling 179 patients in ten-minute slots. All patients underwent a similar protocol using different $1.5 \mathrm{~T}$ scanners from a single vendor (Siemens AG), consisting of orthogonal localizers, two-chamber localizer, single-slice short-axis prototype $\mathrm{T} 1$ MOLLI and T2* multiecho acquisition of the heart and single-slice transaxial slice of the liver with $\mathrm{T} 1$ and $\mathrm{T} 2^{*}$ sequences. Automated maps for both $\mathrm{T}^{*}$ and $\mathrm{T} 1$ were generated by an in-line processing prototype software. T2* results were also obtained by manual calculation using a ROI-based fit and truncation. In a subgroup of sixteen patients, left-ventricle function was also assessed using a sparse sampling and iterative reconstruction cine technique with a repeat scan using traditional $\mathrm{T} 2 *$ sequences plus cine-SSFP imaging. Endpoints of the study included the time required for each exam, the accuracy of the automatically calculated $\mathrm{T} 2 \%$ values compared to the manual analysis as well as factors associated with duration of the exam and successful completion of the protocol.

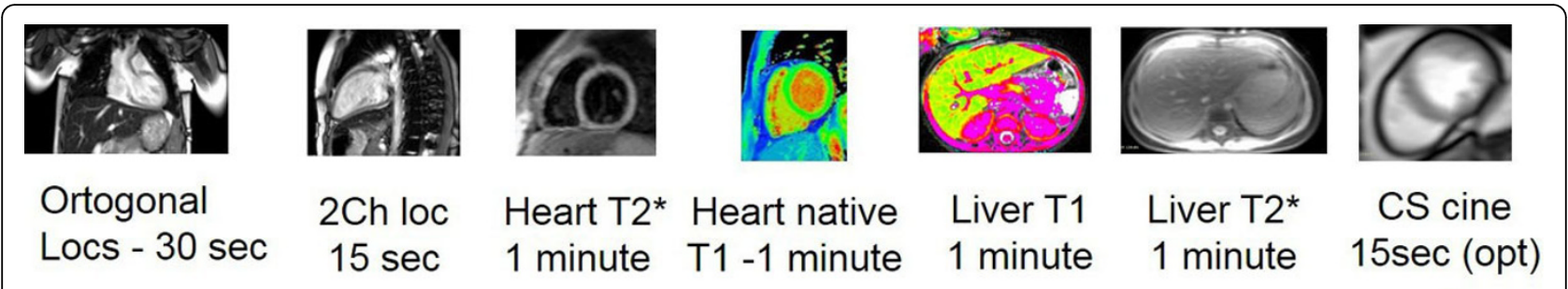

Total scan time: 5-6 minutes

Figure 1

'Jose Michel Kalaf Research Institute, Campinas, Brazil

Full list of author information is available at the end of the article 


\section{Results}

The mean age of participants was $27.5 \pm 20.1$ years (range 2 to 91 years) with $51 \%$ females and $44 \%$ children/adolescents. The median scan time was 5.2 minutes (IQR 4 to 7 minutes). For the heart, Bland-Altman plots demonstrated a mean difference of $-1.2 \mathrm{~ms}$ ( $95 \% \mathrm{CI}-1.7$ to $-0.8 \mathrm{~ms})$ for the automated maps compared to the manual analysis. In the liver, this difference was $-0.18 \mathrm{~ms}$ (95\%CI -0.30 to $-0.06 \mathrm{~ms})$. In only $1.1 \%$ of the patients, the heart $\mathrm{T} 2 *$ values could not be calculated due to motion; all liver $\mathrm{T} 2 \%$ values were obtained. Age, sex, etiology and hemoglobin levels did not affect the total exam time while significant differences were observed among the centers $(\mathrm{P}<0.001)$. In the subgroup of sixteen patients with repeat scans including cine imaging, there were significant differences in total time of scan $(7.5 \pm 1.8 \mathrm{~min}$ vs $10.2 \pm 2.5 \mathrm{~min}, \mathrm{P}=0.001)$.

\section{Conclusions}

Use of an accelerated protocol for acquisition and calculation of iron overload in the liver and heart is feasible and results in successful completion of the study in the majority of patients with similar values compared to manual analysis.

\section{Funding}

N/A.

\section{Authors' details}

'Jose Michel Kalaf Research Institute, Campinas, Brazil. ${ }^{2}$ Radiologia Clinica de Campinas, Campinas, Brazil. ${ }^{3}$ Santa Joana Diagnostico, Recife, Brazil. ${ }^{4} \mathrm{Hospital}$ Sirio Libanes, Sao Paulo, Brazil. ${ }^{5} \mathrm{CDPI}$, Rio de Janeiro, Brazil. ${ }^{6} \mathrm{DASA}$, Sao Paulo, Brazil. ${ }^{7}$ Hospital Ana Nery, Salvador, Brazil. ${ }^{8}$ Siemens Ltda, Sao Paulo, Brazil. ${ }^{9}$ Hospital Mater Dei, Belo Horizonte, Brazil. ${ }^{10}$ Siemens AG, Erlangen, Germany.

Published: 3 February 2015

doi:10.1186/1532-429X-17-S1-062

Cite this article as: Fernandes et al:: Use of an accelerated protocol for rapid analysis of iron overload in the heart and liver: the All Iron

Detected (AID) Multicenter Study. Journal of Cardiovascular Magnetic Resonance 2015 17(Suppl 1):062.
Submit your next manuscript to BioMed Central and take full advantage of:

- Convenient online submission

- Thorough peer review

- No space constraints or color figure charges

- Immediate publication on acceptance

- Inclusion in PubMed, CAS, Scopus and Google Scholar

- Research which is freely available for redistribution

Submit your manuscript at www.biomedcentral.com/submit
C Biomed Central 